\title{
O USO DA TECNOLOGIA DIGITAL DA INFORMAÇÃO E COMUNICAÇÃO COMO FERRAMENTA DIDÁTICA PARA O ENSINO DE BIOLOGIA CELULAR NO ENSINO MÉDIO
}

Amanda do Amaral Luna

Instituto Federal do Sudeste de Minas Gerais- Campus Barbacena

Rua Monsenhor José Augusto, nº 204 - Bairro São José - CEP: 36205-018 - Barbacena - MG

\section{RESUMO}

$\mathrm{Na}$ aprendizagem de Biologia Celular no ensino médio, muitas vezes, surge receios pelos estudantes antes mesmo de terem contato com o conteúdo, devido à falta de compreensão pelos alunos da estrutura e funcionamento celular. Por isso, buscou-se com este estudo criar estratégias de ensino que despertassem o interesse do estudante pela disciplina, e ao mesmo tempo contribuísse para a assimilação de conceitos de Biologia Celular de forma significativa. O objetivo dessa pesquisa foi apresentar a eficácia da utilização das mídias na educação e as TDICs, trazendo uma breve demonstração desses recursos no ensino de Biologia Celular para serem trabalhados com alunos do primeiro ano do ensino médio. A metodologia utilizada neste trabalho foi revisão bibliográfica em que foram selecionados autores que citavam a importância da introdução de TDICs utilizadas no ensino e suas contribuições para o ensinoaprendizagem de Biologia e após foram criados conteúdos abordados no primeiro ano do ensino médio como proposto pela BNCC, usando como apoio o livro didático e os softwares, Pixton, Canva e Phet colorado. O uso das TDICs no ensino se mostrou um recurso didático moderno que muitas vezes já faz parte do cotidiano dos alunos, deixando a disciplina mais atrativa aproximando os alunos e permitindo uma melhor assimilação do conteúdo estudado. Entretanto muitos professores podem apresentar dificuldades com essas tecnologias, por isso é importante as escolas oferecerem uma capacitação para professores a fim de que eles superem essas dificuldades tecnológicas e tragam para sala de aula uma metodologia diversificada para seus alunos.

Palavras-chave: Didática; Ensino de biologia; Ensino Médio; Formação de professores; Tecnologia.

*Autor correspondente: Amanda do Amaral Luna, graduada em Ciências Biológicas e especialista em Biologia Celular e Molecular, Paiva MG. Telefone: (32) 998319475; E-mail: amandalunna16@gmail.com 


\section{INTRODUÇÃO}

$\mathrm{Na}$ aprendizagem de Biologia Celular no ensino médio, muitas vezes, surge receios pelos estudantes antes mesmo de terem contato com o conteúdo, devido à falta de compreensão pelos alunos da estrutura e o funcionamento celular. Por isso, buscou-se com este estudo criar estratégias de ensino que despertassem o interesse do estudante pela disciplina, e ao mesmo tempo contribuísse para a assimilação de conceitos de Biologia Celular de forma significativa.

Para tal, propôs-se o uso de mídias na educação e tecnologias digitais de informação e comunicação (TDICs) em sala de aula como, softwares e aplicativos de celular, por se tratar de uma ferramenta que pode ser usada no ensino como um recurso didático moderno, por fazer parte do cotidiano dos discentes, o que pode deixar a disciplina mais atrativa aproximando os alunos do conteúdo a ser abordado. Entretanto se faz necessário a capacitação para professores a fim de preparálos para essa inserção no meio tecnológico, para que possam dominar essa nova ferramenta de ensino.

Diversos autores como Costa, Duquevi e Pedroza (2015), Camillo e Camillo (2020) e Gomes (2014) citam a contribuição das TDICs no ensino, como uma melhor assimilação dos conteúdos pelos alunos, incentivo a formação de indivíduos críticos e interesse pelo conteúdo estudado.

O objetivo dessa pesquisa foi apresentar a eficácia da utilização das mídias na educação e as TDICs, como o uso de histórias em quadrinhos, softwares e aplicativos de celular, trazendo uma breve demonstração desses recursos no ensino de Biologia Celular para serem trabalhados com alunos do primeiro ano do ensino médio.

Segundo Gomes (2014) as tecnologias estão a cada dia mais presente na vida das pessoas devido à expansão tecnológica. As informações chegam o tempo todo através das tecnologias, nos permitindo mudar a didática educativa. É importante que os docentes saibam aproveitar essa ferramenta no ensino, com intuito de auxiliar no processo de ensino e aprendizagem dos alunos, pois com o estímulo das tecnologias passa a ser um diferencial nas aulas e atividades propostas pelo componente curricular se tornando mais atrativo, pois o aluno se torna protagonista do seu processo de ensino-aprendizagem.

Este estudo teve como base metodológica a revisão bibliográfica em que foram selecionados autores que abordavam a importância da introdução de tecnologias no ensino, as TDICs utilizadas no ensino de Biologia Celular e suas contribuições para o ensino-aprendizagem de Biologia.

\section{METODOLOGIA}

O presente trabalho teve como metodologia de pesquisa um levantamento bibliográfico, em que foram selecionados artigos das bases de dados do Google Acadêmico e SciELO. Livros sobre ensino de Moran, Masetto e Behrens (2001), Novas tecnologias e mediação pedagógica e Krasilchik (2004), Prática de ensino de Biologia, e o livro didático de Lopes e Rosso (2016). A busca foi realizada no período de dezembro de 2020 a junho de 2021. Os critérios de inclusão estabelecidos foram os artigos que citavam a utilização de TDICs no ensino de Biologia com ênfase no ensino de Biologia Celular.

No primeiro momento a partir dos dados obtidos criou-se conteúdos abordados no primeiro ano do ensino médio como proposto pela Base Nacional Comum Curricular, usando como apoio o livro didático de Lopes e Rosso (2016) com os softwares, Pixton, Canva e Phet colorado.

No segundo momento foi selecionado as ferramentas a serem utilizadas com base no que foi citado pelos artigos, como o software Pixton, trabalhando as diferenças das células eucariontes e procariontes com a criação de $H Q$, o Canva na criação de mapa mental abordando os conceitos que envolvem a organização citoplasmática das células, e o Phet colorado na simulação de canais de membrana.

No terceiro momento foi elaborado pela pesquisadora um enredo para a criação da 
$H Q$, mapa mental e a simulação com base no conteúdo do livro didático.

No último momento discutiu-se a importância das TDICs para o ensino de Biologia.

\section{RESULTADOS}

No âmbito educacional, percebe-se maior interesse dos alunos por mídias e uso de tecnologias e muitas vezes um desinteresse e desmotivação por conteúdos muito teóricos e conceituais. Nesse caso se torna necessário a apresentação de métodos alternativos que estimulem o interesse e a participação dos alunos ao longo do processo de ensinoaprendizagem. $O$ art.12 das Diretrizes Curriculares Nacionais de Educação Básica (BRASIL, 2013), cita que, é importante proporcionar ao aluno um método atraente para o aprendizado de Biologia, em que se devem adotar metodologias de ensino e de avaliação de aprendizagem que estimulem a iniciativa dos estudantes. O docente poderá usar de sua criatividade para ter um melhor aproveitamento do conteúdo a ser aplicado, atingindo seus objetivos de ensino.

De acordo com Santos, Silva e Acioli (2012), as tecnologias estão cada vez mais presentes oportunizando ampla socialização, criando espaços de construção e troca de conhecimentos entre os indivíduos, aproximando e promovendo um avanço na comunicação. Neste sentido, entende-se que as várias inovações tecnológicas podem auxiliar na promoção de mudanças educacionais.

Entretanto há uma resistência com os professores de escola pública, como cita Figueiredo (2014), os docentes advindos de escolas públicas, não fazem a utilização das mídias tecnológicas e demais recursos tecnológicos muitas vezes por falta de qualificação, falta de tempo, de interesse, a não adequação ao laboratório de informática. Se diferindo dos docentes do ensino superior, que efetivam projetos de extensão e iniciação a pesquisa, não conseguem acompanhar o aluno no contexto tecnológico e pedagógico por muitas vezes estar se adequando a fluidez do paradigma tecnológico. Vejamos o que alguns autores explicam sobre isso:

É necessário a inserção das (TDICs) no contexto escolar e que faça parte do currículo de formação de professores. Para que estas, não apenas esteja presente, mas sim, contribua com que o aluno se torne um indivíduo crítico, criativo e saiba se posicionar perante a sociedade. (CAMILLO; CAMILLO, 2020).

Os autores Moran, Masetto e Behrens (2001) discutem que o uso dessas tecnologias também se desenvolve processos de aprendizagem à distância, em que são utilizadas listas, os grupos de discussão, elaboração de relatórios de pesquisa, construção em conjunto de conhecimentos. Os e-mails colocam professores e alunos em contato fora dos horários de aula, facilitando a troca de informações e trabalhos a distância e num tempo de grande velocidade, possibilitando a troca de dados nos mais diversos centros de pesquisa através da internet. $\mathrm{Na}$ atualidade em que vivemos sabemos da importância de saber utilizar esses meios tecnológicos, "é importante auxiliar o aluno a refletir sobre o uso da internet, indiferente do espaço que está inserido. Interpretar mensagens ou identificar se uma fonte de notícia e de estudo é confiável, faz parte também da educação tecnológica". (CAMILLO; CAMILLO, 2020).

\subsection{O USO DE TDICs NO ENSINO DE CIÊNCIAS BIOLÓGICAS}

Atualmente 0 ensino de Ciências Biológicas passa por dificuldades em chamar a atenção do aluno, por apresentar conteúdos que requerem interpretação de conceitos biológicos, e muitas vezes são somente empregadas aulas expositivas o que não leva a participação dos alunos. Para auxiliar professores e alunos nesse processo de ensino e aprendizagem, as TDICs oferecem diversas possibilidades de criar e visualizar conteúdos que na prática seriam difíceis ou 
impossíveis de serem observados, desta forma auxiliando o aluno a compreender melhor os conteúdos.

As tecnologias da informação e comunicação (TICs) estão presentes no cotidiano, são essas tecnologias que trazem e mandam informação para as pessoas, um exemplo são os dispositivos eletrônicos e tecnológicos, incluindo-se computador, internet, tablet e smartphone. As TICs abrangem tecnologias mais antigas como a televisão, o jornal e o mimeógrafo, pesquisadores têm utilizado o termo Novas Tecnologias para se referir às tecnologias digitais (KENSKI, 1998 apud COSTA; DUQUEVIZ; PEDROZA, 2015) ou Tecnologias Digitais da Informação e Comunicação (TDICs) uma tecnologia avançada que engloba o uso da internet por meio de aplicativos e softwares.

Segundo Moraes (2016) estudos demonstram que recursos didáticos são instrumentos pedagógicos capazes de promover o aprendizado de maneira lúdica e interessante, munindo os profissionais com ferramentas atuais e eficientes, promovendo junto aos estudantes ganhos significativos na relação ensino-aprendizagem. O autor cita a utilização de estratégias inovadoras no uso de recursos didáticos para o ensino de Ciências Biológicas, em que foram produzidos e/ou utilizados modelos didáticos, jogos educativos, cartilhas em quadrinhos e o software aplicativo Scratch como estratégias didáticas, aplicadas com alunos do ensino fundamental II e segundo ano do ensino médio de uma escola pública na Bahia. $O$ uso de estratégias inovadoras mostrou-se de grande aceitação pelos estudantes, promovendo melhorias para o ensino-aprendizagem de Ciências Biológicas.

O uso de softwares educacionais tem sido utilizado no ensino de Biologia e outras disciplinas. Esse recurso de aprendizagem permite ao aluno observar o funcionamento de um determinado sistema. Dentre eles podemos citar o simulador Phet Colorado, uma ferramenta computacional que proporciona o processo de aprendizagem, motivando os alunos e professores e a interatividade. Assim como fez Gregório, Oliveira e Matos (2016) no ensino de Biologia para o ensino de síntese proteica, e de Paula et al. (2014) que realizou uma análise de softwares educacionais, entre eles foi utilizado o Phet no ensino de Física, Biologia e Química, como resultado obtiveram um potencial de colaborar na aprendizagem dos alunos tendo um engajamento expressivo e uma visão positiva no uso da simulação como estratégia metodológica dos conteúdos abstratos se utilizados de forma planejada e com objetivos bem definidos pelos professores.

Segundo Gomes (2014) Vários recursos midiáticos têm sido utilizados na contribuição de uma aprendizagem significativa através de instrumentos, tais como blog, flog, vídeos, webquest, hipertextos, chats, fóruns de discussão, mapas conceituais, portfólio, diário de bordo, msn, twitter, wiki. Esses recursos podem ser importantes estratégias no processo de ensino-aprendizagem, fazendo sua utilização em sala de aula de maneira efetiva e eficaz, elaborando, a partir desses elementos, propostas didáticas de incentivo a formação de indivíduos críticos, criativos, participativos, interessados, com autoria e autonomia.

Martins (2019) desenvolveu o Website educacional "www.celuladidatica.ufpr.br", classificado como repositório temático, na área de Biologia Celular, que se constitui em uma coleção de objetos educacionais selecionados sobre estrutura e função celular, que disponibiliza recursos digitais motivadores, de relevância científica e facilitadores do processo de ensino aprendizagem, agrupados por conteúdos relativos à estrutura e função celular. O autor ainda menciona a importância de investir na formação inicial e continuada de professores produtores de objetos educacionais digitais e estimular essa atividade por meio de políticas educacionais específicas.

A criação de histórias em quadrinhos (HQs) como recurso didático tem sido frequentemente utilizada através do software Pixton, desenvolvido pela empresa Pixton Comics Inc.@, é uma ferramenta direcionada para a criação de histórias em quadrinhos, voltada para professores e alunos, empresas e pessoas que buscam criar HQs.

Souza (2015) utilizou o software Pixton 
na produção de HQs como uma ferramenta funcional para trabalhar determinados conteúdos curriculares, como o conteúdo de respiração celular aeróbica voltado para alunos do primeiro ano do ensino médio. Em seu estudo, apresentou uma alternativa de prática pedagógica que permita contribuir no processo de aprendizagem dos alunos, em relação ao conteúdo proposto.

Camillo e Camillo (2020) realizaram um mapeamento nos anais do Simpósio Internacional e Nacional de Tecnologias Digitais na Educação (SNTDE) no período compreendido entre os anos de 2016 a 2019, a fim de verificar quais recursos tecnológicos estão sendo utilizados no ensino de Ciências Biológicas e qual a sua importância para o ensino e aprendizagem.

Os autores constataram que os recursos tecnológicos utilizados foram: softwares, plataformas de objetos de aprendizagem e de recursos educacionais aberto, vídeos, aplicativos móveis, como o game RecycleMax, um jogo sobre a reciclagem e preservação do meio ambiente, plataforma Kahoot, um Quis sobre citoplasma celular e núcleo celular, Microsoft Publisher na construção de textos, gráficos para exposição de fotos da biodiversidade ecológica, software Canva em representações gráficas com o tema evolução e o aplicativo PlantSnap que identifica a planta ao tirar a foto por meio do celular, que logo em seguida aparece na tela o nome e informações sobre a planta. Segundo os autores na grande maioria dos artigos ficou evidente que os alunos se sentiram motivados ao utilizar as tecnologias educacionais e que é necessária a reivindicação de políticas públicas eficiente, para que as escolas e os professores possam se especializar, a fim de trabalhar com as TDICs (CAMILLO E CAMILLO, 2020).

\subsection{CRIAÇÕES DE HQS COM SOFTWARE PIXTON}

A plataforma do Pixton oferece diversas opções de acesso: EDU Educador para educadores e professores, EDU Solo Student para alunos que usam o Pixton por conta própria e Pixton PRO para usuários corporativos e revendedores (Fig. 1). $\mathrm{O}$ acesso ao site se dá por meio do endereço eletrônico: http://www.pixton.com/. Ao escolher a opção o usuário poderá se cadastrar e experimentar alguns recursos gratuitos na plataforma, criando um login e senha. A versão experimentada foi a Pixton EDU educador. Após efetuar o cadastro o usuário terá acesso ao "meu painel", com opções de editar o avatar, adicionar pacotes de conteúdo, sendo oferecido uma opção de pacote grátis e o restante pago. Na opção adicionar pacotes, o usuário será direcionado a uma página com diversas opções de pacotes de conteúdo de acordo com a área de conhecimento desejada, como mostra na Fig. 2. Na versão gratuita não e possivel baixar as HQs e fazer a impressão, somente pagando um pacote mensal ou anual.

Figura 1 - Página Inicial do Software Pixton

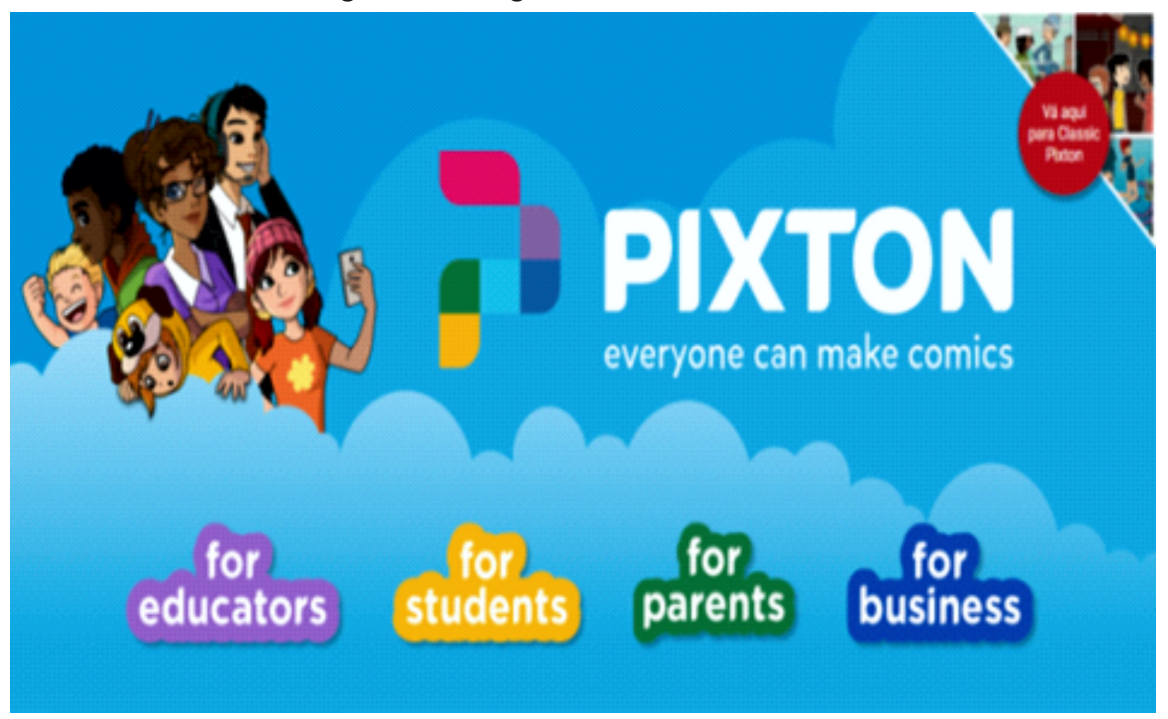

Figura 1 - Página Inicial do Software Pixton 
Figura 2 - Opções de Pacotes de Conteúdo

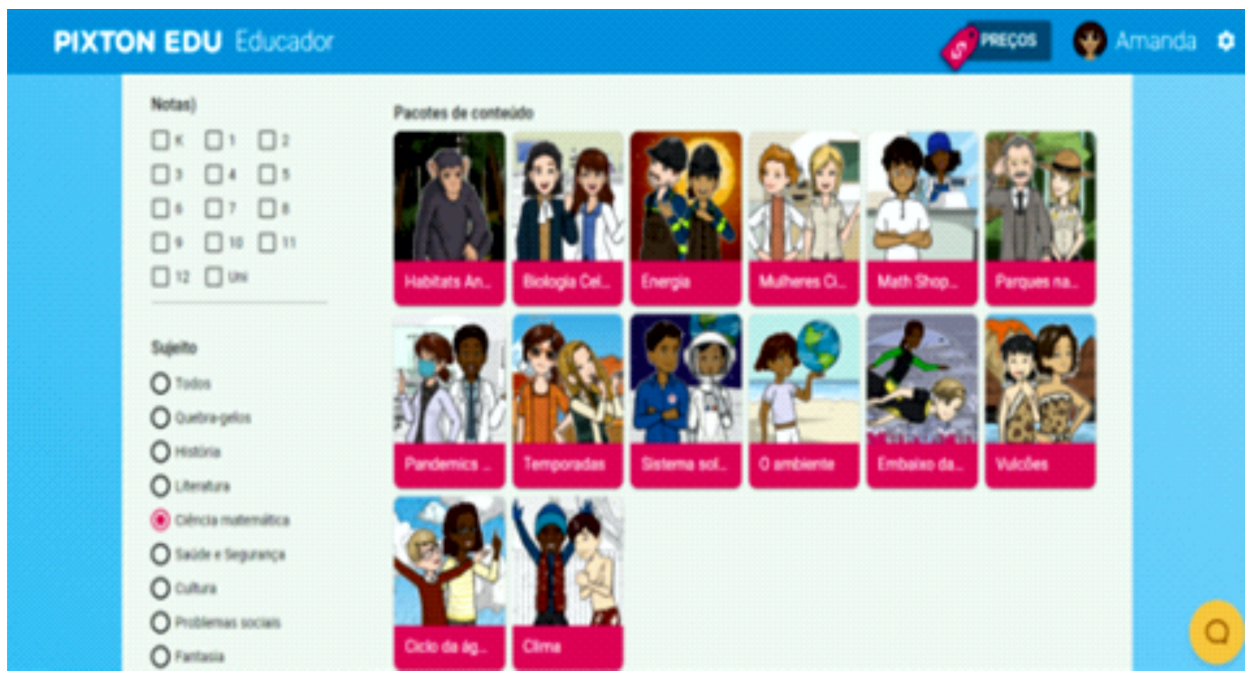

Fonte: Pixton (2020)

A HQ apresentada sobre o tema Célula Procarionte e Eucarionte (Fig. 3), foi criada na versão anterior do Pixton clássico que se encerrou em dezembro de 2020. A plataforma disponibilizou para todos os usuários da modalidade gratuita as opções de baixar e imprimir para que não perdessem as HQs criadas, como foi feita neste trabalho. Tanto a versão anterior quanto a atual oferecem opções de inserção de balões e falas, personagens, variedades de quadrinhos, porém a versão anterior oferecia uma variedade maior de cenários gratuitos, entretanto a versão atual inovou a opção de cenários acrescentando conteúdos relevantes aos temas abordados em sala de aula, trazendo exemplos prontos de imagens de fundo e esquemas, enriquecendo as HQs de conteúdos exemplificados.

$\mathrm{Na}$ Fig. 3 é apresentado o estudo de células eucariontes e procariontes em que são abordadas na $\mathrm{HQ}$ as principais diferenças entre elas, com a inserção de imagens e esquemas, a fim de facilitar a assimilação do leitor.

Figura 3 - HQ Sobre o Tema Célula Procarionte e Eucarionte

Célula procarionte e eucarionte

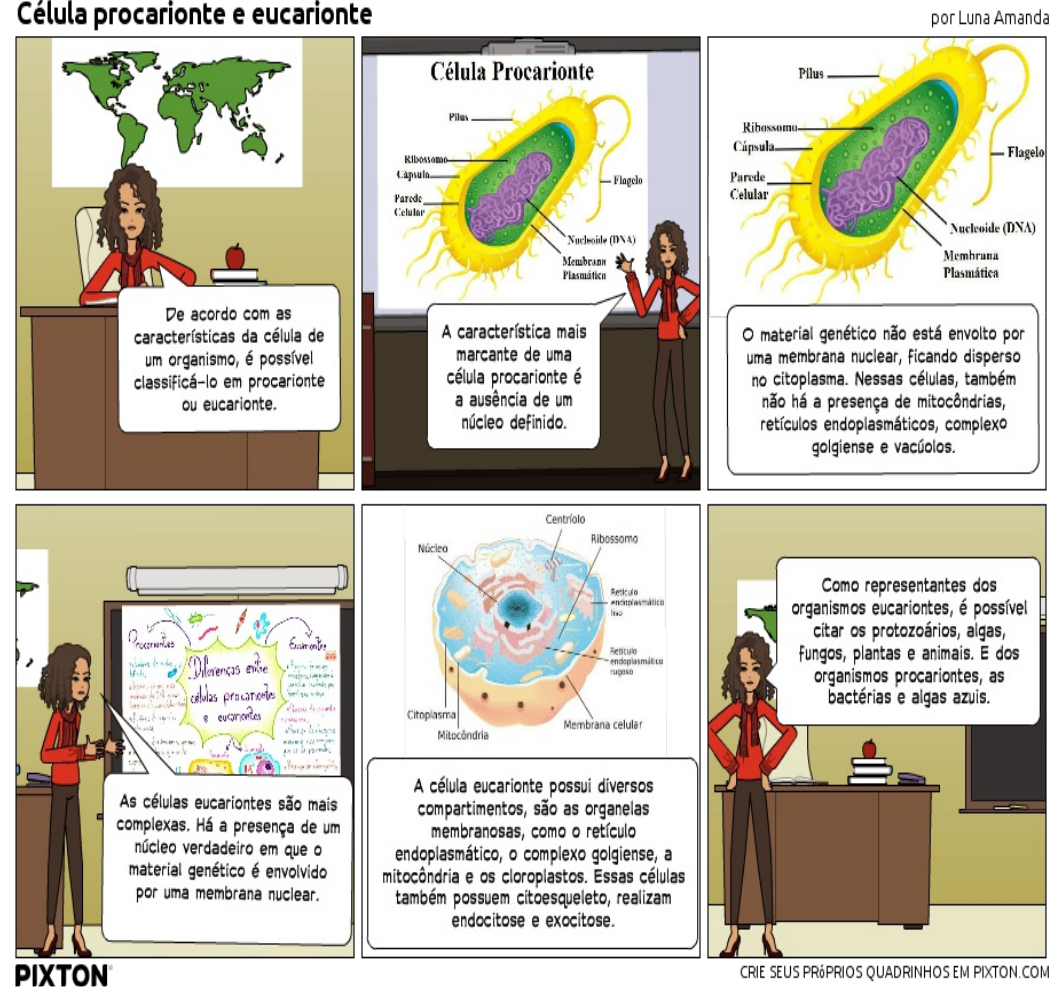

Fonte: Pixton (2020) e brasilescola.uol.com.br (2020) 
Conforme Krasilchik (2004), muitos dos alunos estão preocupados com as notas que irão tirar e a necessidade de passar nas avaliações, se preocupam com a demanda que o professor passa e em agradá-lo. Memorizam os conteúdos de forma desconexa apenas para atender as exigências escolares.

Assim como citam Silva e Falkembach (2010), as HQs possuem um grande potencial como recurso didático, é um facilitador na aprendizagem do estudante, em diversas áreas do conhecimento. Possibilita uma nova visão sobre o assunto, auxilia na compreensão de conteúdo formal, partindo de situações problemas expostos a realidade do estudante, atua no desenvolvimento da leitura e da interpretação de texto, incentivando o leitor a novas leituras, tornando o processo de ensino e aprendizagem mais agradável.

\subsection{SIMULAÇÕES INTERATIVAS COM PHET COLORADO}

O Software Phet colorado oferece simulações de Matemática, Física, Química e Biologia, são interações gratuitas baseadas em pesquisas. O acesso se dá pelo site: https:// phet.colorado.edu/. O usuário deverá selecionar a disciplina e o conteúdo a ser trabalhado (Fig. 4), após isso será possível criar animações com os recursos fornecidos.

Figura 4 - Página Inicial do Simulador Phet Colorado

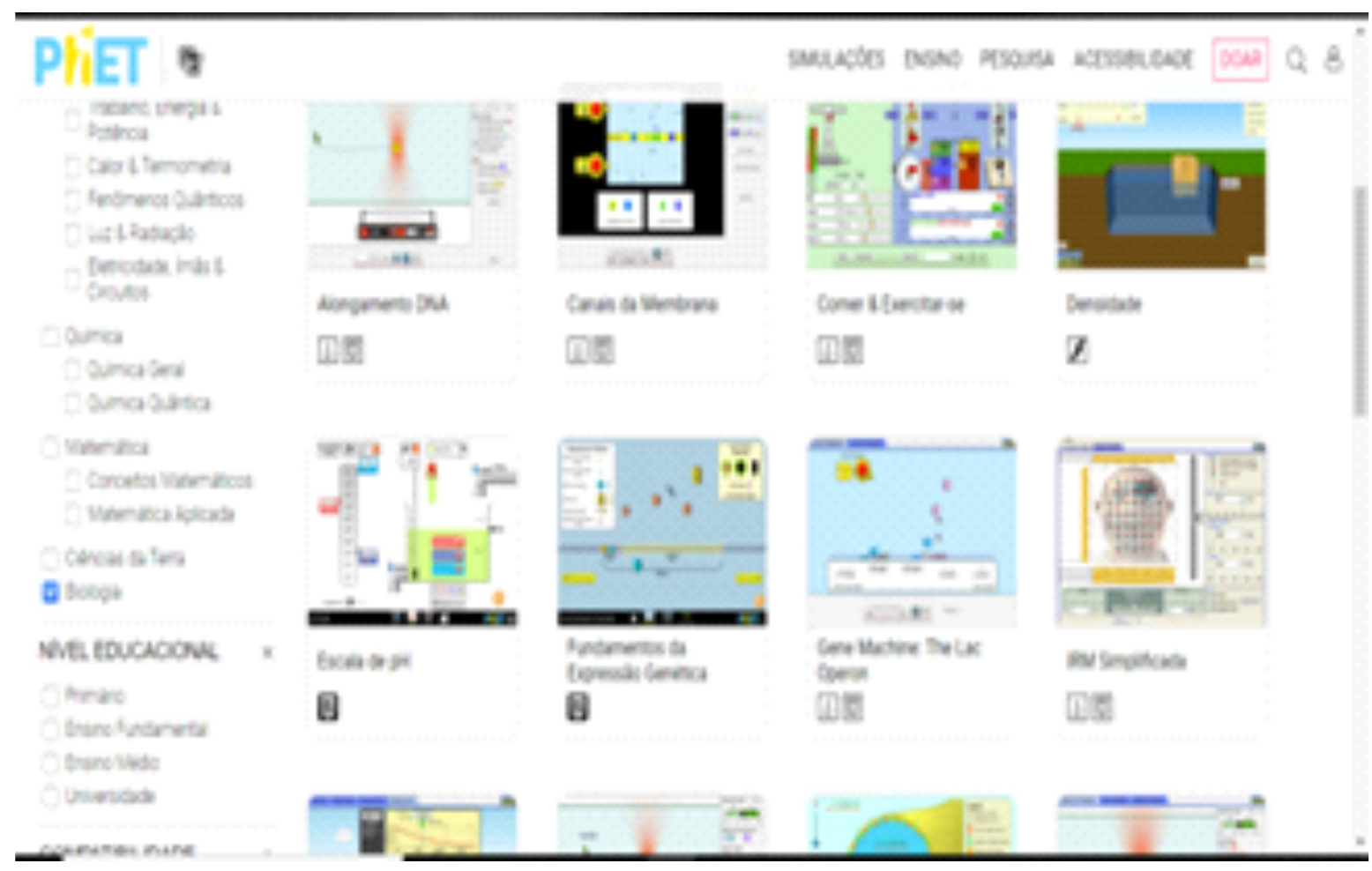

Fonte: Phet Colorado (2020)

De acordo com os autores Lopes e Rosso (2016), no estudo de processos de troca entre a célula e o meio externo, podemos citar os processos de passagem de partículas do soluto através da membrana plasmática, os íns e moléculas atravessam a membrana através de transporte passivo sem gasto de energia, tendendo a igualar a concentração da célula com o meio externo (a favor do gradiente de concentração) ou por transporte ativo com gasto de energia, mantendo diferença de concentração entre a célula e o meio externo, (contra o gradiente de concentração). No transporte passivo envolve mecanismos de difusão com a ajuda de moléculas carreadoras chamado de difusão facilitada ou difusão simples, sem ajuda, passando diretamente pela membrana. 
Figura 5 - Simulação Canais de Membrana

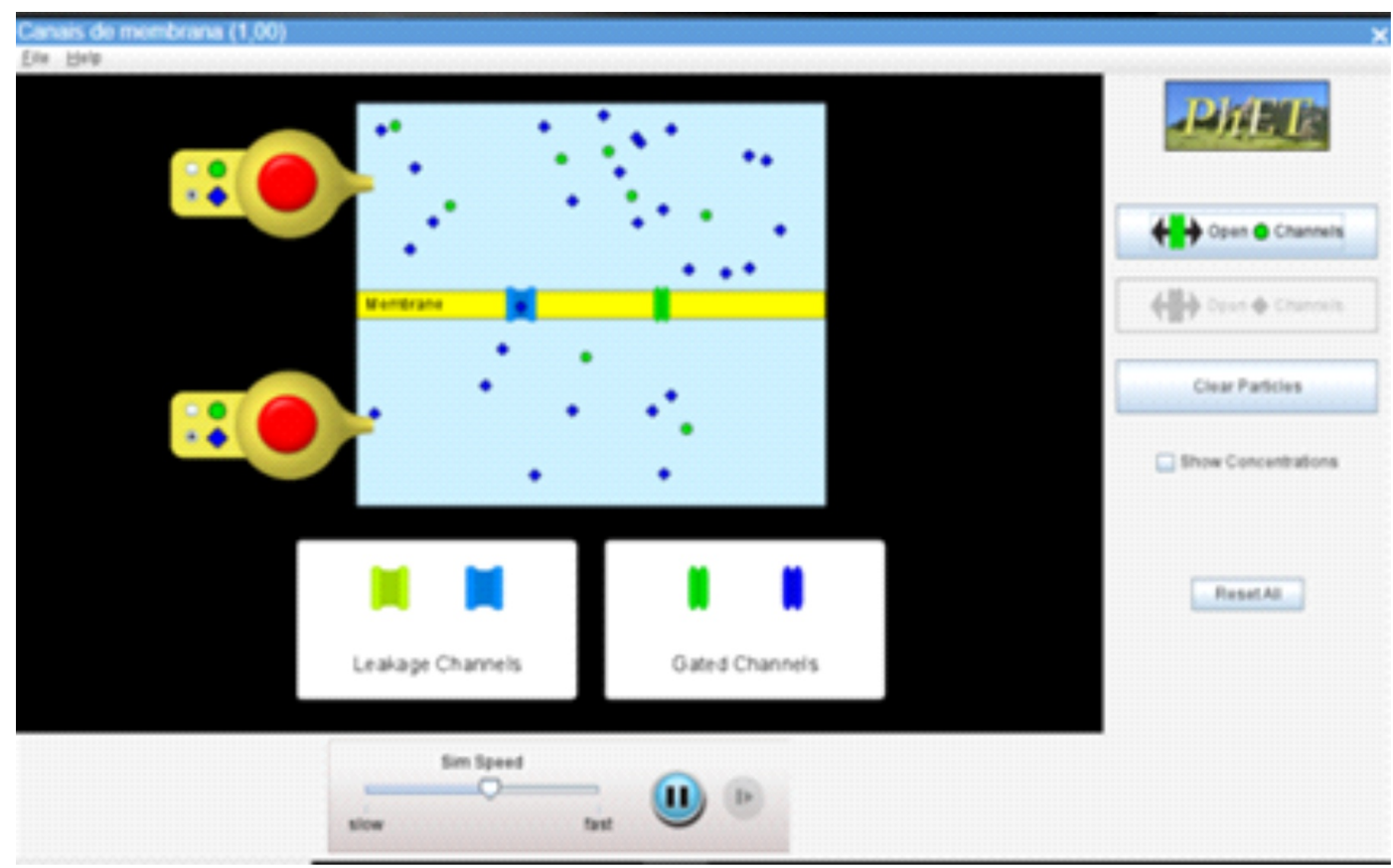

Fonte: Phet Colorado (2020) e Lopes e Rosso (2016)

Na Fig. 5 é demonstrado um esquema sobre os canais de membrana exemplificando o processo de difusão simples, as moléculas atravessam a membrana plasmática pela própria camada lipídica ou por proteínas de canal (representado pela cor azul), as substâncias que conseguem atravessar a bicamada lipídica são chamadas de lipossolúveis, como $\mathrm{O} 2$ e $\mathrm{CO} 2$. Na difusão facilitada, as substâncias também se movimentam através de proteínas carreadoras (representado na cor verde), nesse transporte facilitado a molécula é fixado na proteína carreadora ocorrendo a transformação conformacional da proteína de modo que o canal passe a ficar aberto para o outro lado da membrana.

Para Gregório, Oliveira e Matos (2016), O ensino de conteúdos abstratos exige metodologias de ensino diferenciadas. A realização de atividades práticas nas escolas no ensino de Biologia Celular se torna um desafio, devido à exigência de equipamentos, materiais que são de grande custo ou a falta de laboratórios nas escolas. $E$ os simuladores virtuais são ferramentas que quando associadas às metodologias de ensino eficientes podem sanar as dificuldades que o processo de ensino e aprendizado de conteúdos abstratos apresenta se tornando uma opção para simular experimentos laboratoriais.

\subsection{ELABORAÇAO DE MAPA MENTAL COM O CANVA}

O Canva é uma plataforma de design gráfico que permite criar gráficos de mídias sociais, apresentações, cartazes, convites e outros conteúdos visuais, com utilidades diversas inclusive sendo aplicada na educação através de mapas mentais. A plataforma oferece a versão gratuita e assinatura paga. Está disponível online no site: https:// www.canva.com/ e em dispositivos móveis. Ao fazer o login, aparecerá na parte superior da plataforma o campo de busca, como mostra na Fig. 6, para ter acesso aos modelos de mapas mentais basta fazer a procura nesse campo por "mapa mental" que será apresentado as opções (Fig. 7). Os usuários podem escolher entre muitos modelos prontos, editar os designs e fazer download de suas próprias criações. 
Figura 6 - Página Inicial do Canva

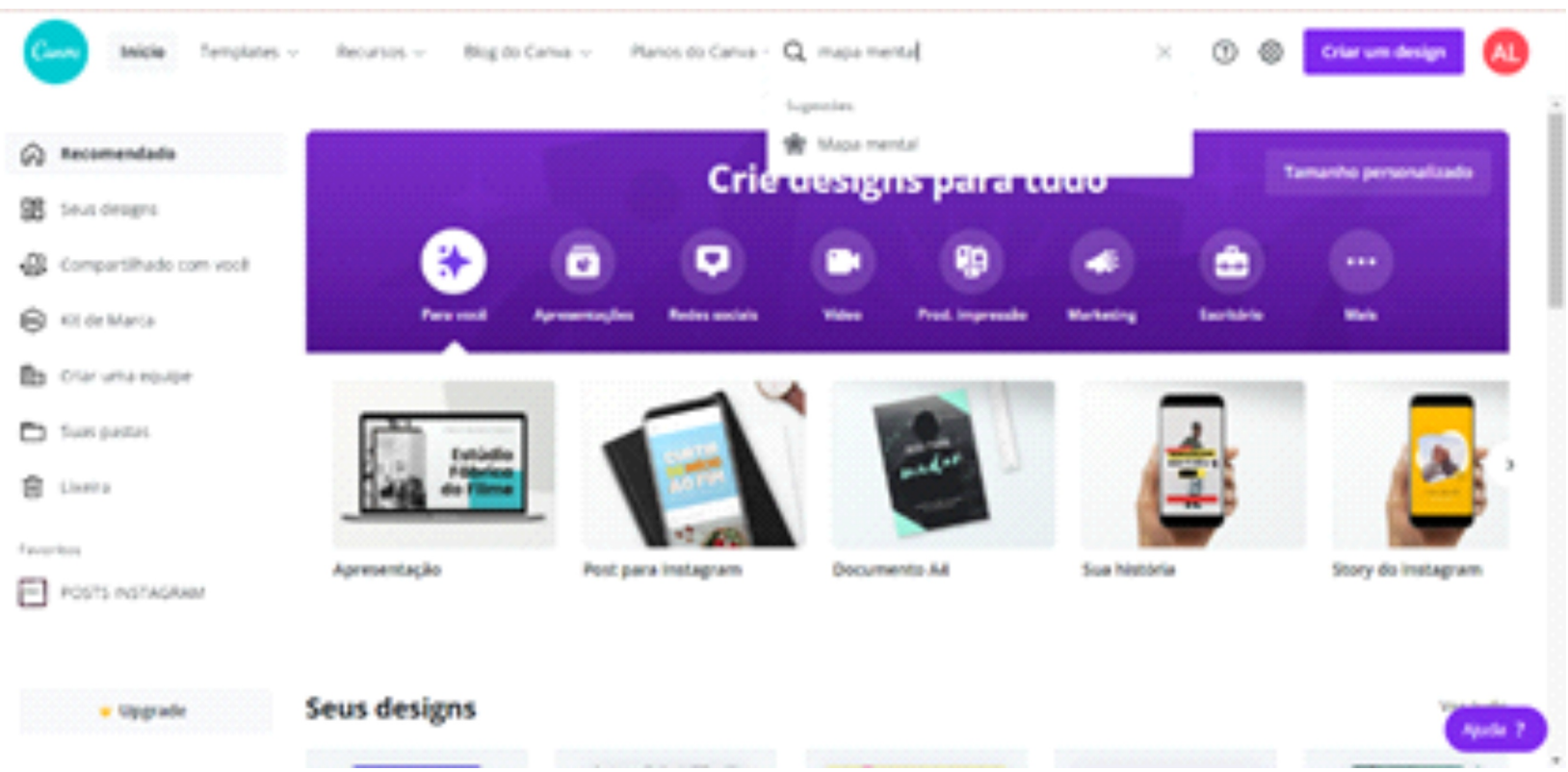

Fonte: Canva (2020)

Figura 7 - Mapa Mental no Canva

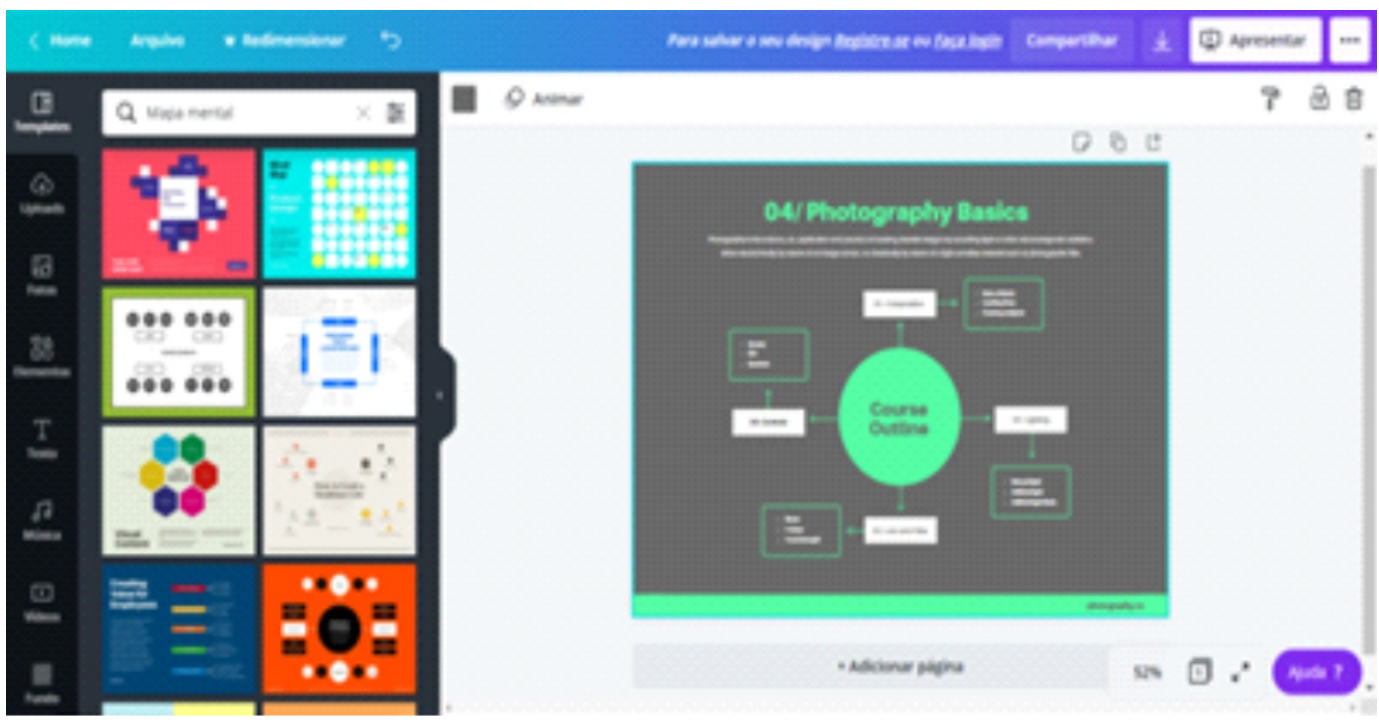

Fonte: Canva (2020)

A utilização da plataforma do Canva possibilita criar mapas mentais e diversos conteúdos com inserção de esquemas, imagens e textos para o meio educativo. Assim como cita Da Silva Santos, Da Conceição e Mota (2019), a criação de mapas mentais permite a percepção dos vários elementos que compõem o todo e suas relações em uma única estrutura, sendo uma proposta para a avaliação dos alunos. O professor é capaz de observar e reconhecer que os estudantes integram a realidade e os elementos do cotidiano, com conhecimentos científicos. Essa ferramenta permite o professor avaliar se os estudantes fazem a correlação do conteúdo estudado e condições de transpor essa informação para o papel. O mapa mental trabalha com a capacidade de expressar através da linguagem gráfica 0 seu conhecimento. 
Figura 8 - Mapa Mental Organelas Citoplasmáticas

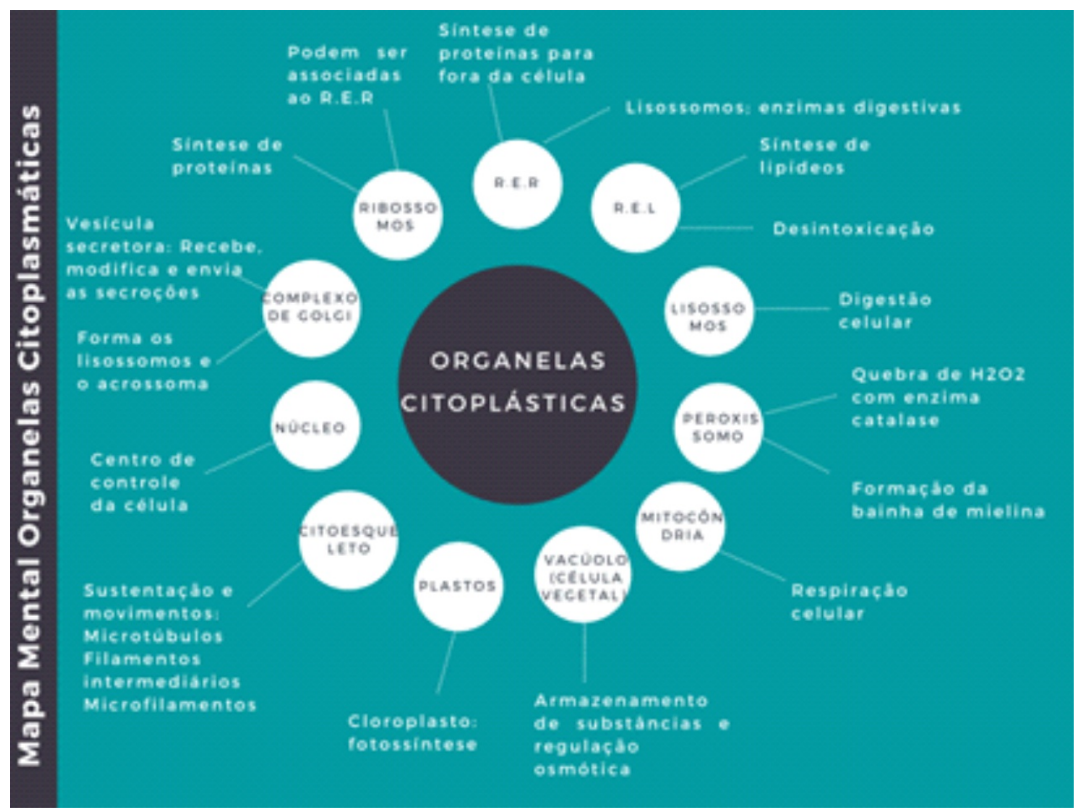

Fonte: Canva (2020) e Lopes e Rosso (2016)

Também poderá ser utilizado pelo professor para organização dos conteúdos como uma forma de resumo para os alunos para uma maior fixação, como exposto na Fig. 8 , em que foi criado um mapa mental sobre o conteúdo de Organelas Citoplasmáticas, sintetizando os conceitos de Lopes e Rosso (2016) que afirmam que as células eucarióticas são mais complexas comparadas as células procarióticas, apresentam um núcleo, organelas citoplasmáticas e um citoesqueleto. Já as procarióticas são mais simples, formado por uma matriz rica em água, íons e moléculas dissolvidos, não apresentam organelas membranosas.

Pode haver membranas especiais no citoplasma dessas células, como as membranas fotossintéticas. Imersos no citoplasma das células procarióticas estão os ribossomos, responsáveis pelo processo de síntese proteica, também presentes nas células eucarióticas. $\mathrm{O}$ material genético encontra-se disperso em uma região da matriz citoplasmática chamado de nucleoide, o material genético é constituído por uma única molécula de DNA. Nas células eucarióticas o citoplasma corresponde entre a membrana plasmática e o envelope nuclear, estrutura membranosa que delimita 0 núcleo. 0 citoplasma dessas células é constituído pelo citosol, um fluído composto de água, íons e substâncias que são necessárias a síntese de moléculas orgânicas, onde estão imersos os ribossomos. São características exclusivas das células eucarióticas, além do núcleo, o tipo de citoesqueleto, responsável pela forma e sustentação interna da célula e movimento do citoplasma e as organelas membranosas (LOPES; ROSSO, 2016).

Para Zurawski, Boer e Scheid (2020), se faz necessário a capacitação de professores, pois pelo atual cenário ocasionado pela pandemia da Covid-19, durante o isolamento social, as mídias sociais se tornaram a única forma de comunicação entre estudantes e professores. Essa situação apresenta-se como um desafio a muitos docentes que não estavam familiarizados com as tecnologias para uma função educativa, exigindo-lhes adaptação, tanto de alunos e de seus familiares. São necessárias novas estratégias de ensino para auxiliar no desenvolvimento dos alunos, procurando mostrar a contextualização dos conteúdos escolares.

Para isso, é importante relacioná-las a elementos que fazem parte da realidade atual dos estudantes. Isso envolve a formação profissional continuada, abrangendo o cognitivo, metodológico e profissional. Entretanto além de uma formação de qualidade é necessária a qualidade das condições da instituição na qual o docente atua. Percebe-se 
que professores comprometidos se restabelecem, agrega, nas tecnologias para aulas interativas e desenvolvem competências necessárias a esta nova realidade, para a continuidade da qualidade do ensino.

\section{CONCLUSÃO}

O uso das TDICs no ensino se mostrou um recurso didático moderno que muitas vezes já faz parte do cotidiano dos alunos, deixando a disciplina mais atrativa aproximando os alunos e permitindo uma melhor assimilação do conteúdo estudado.

Entretanto ainda cabe ressaltar que diante do cenário atual, com a retomada das aulas à distância, devido à pandemia da Covid19, muitos professores podem apresentar dificuldades com essas tecnologias, por isso é importante as escolas oferecerem uma capacitação para professores afim de que eles superem essas dificuldades tecnológicas e tragam para sala de aula uma metodologia diversificada para seus alunos, saindo do convencional quadro e giz quando as aulas presenciais forem retomadas.

\section{CONFLITOS DE INTERESSE}

Declaro que não há conflito de interesse na pesquisa.

\section{REFERÊNCIAS}

BRASIL. Ministério da Educação. Secretaria de Educação Básica. Diretrizes Curriculares Nacionais Específicas da Educação Básica. Brasília: MEC, SEB, 2013. $562 p$.

CAMILLO, C. M; CAMILLO, D. T. Mapeamento das tecnologias digitais no ensino de ciências biológicas. In: Anais Do Encontro Virtual De Documentação Em Software Livre E Congresso Internacional De Linguagem $E$ Tecnologia Online. v. 9, n. 1, 2020.

COSTA, S. R. S; DUQUEVIZ, B. C; PEDROZA, R. L. S. Tecnologias digitais como instrumentos mediadores da aprendizagem dos nativos digitais. Psicol. Esc. Educ., Maringá, v. 19, n. 3, p. 603-610, dez. 2015.

DA SILVA SANTOS, C. R; DA CONCEIÇÃO, A. R; MOTA, M. D. A. A utilização dos mapas mentais como instrumento avaliativo no ensino de biologia. In: VI CONGRESSO NACIONAL DE EDUCAÇÃO, Fortaleza, 2019.

DE PAULA, A. C et al. Softwares educacionais para o ensino de física, química e biologia. Revista Ciências \& Ideias, v. 5, n.1, jan.-abr. 2014.

FIGUEIREDO, L. K. A utilização dos recursos tecnológicos na sala de aula: Uma experiência Alagoana. 2014. Disponível em EBOOK - XVII Encontro Nacional de Prática de Ensino - ENDIPE. Acesso em: 09 dez. 2020.

GOMES, J. H. Utilização dos recursos midiáticos como estratégias de aprendizagem no ensino de ciências na formação de professores. Revista EAD em Deb@te, v. 1, n. 1, 2014.

GREGÓRIO, E. A; OLIVEIRA, L. G; MATOS, S. A. Uso de simuladores como ferramenta no ensino de conceitos abstratos de Biologia: uma proposição investigativa para o ensino de síntese proteica. Experiências em ensino de Ciências, v. 11, n. 1, p. 101-125, 2016.

KRASILCHIK, M. Prática de ensino de biologia. 4. ed. São Paulo: EdUSP, 2004. 200 p.

LOPES, S.; ROSSO, S. BIO - volume 1, $3^{\circ}$ ed. São Paulo: Editora Saraiva, 2016. 288p

MARTINS, D. S. Desenvolvimento de website como apoio ao processo de ensino aprendizagem em biologia celular no ensino médio. Curitiba. 2019. Disponível em: <https:// www.acervodigital.ufpr.br/handle/1884/64009> Acesso em 10 dez. 2020.

MORAES, T. S. Estratégias inovadoras 
no uso de recursos didáticos para o ensino de ciências e biologia. 2016. 145f. Dissertação (Mestrado Profissional Gestão e Tecnologia Aplicadas à educação). Universidade do Estado da Bahia, Salvador, 2016.

MORAN, J. M.; MASETTO, M. T.; BEHRENS, M. A. Novas tecnologias e mediação pedagógica. 4. ed. São Paulo: Papirus, 173 p., 2001.

SANTOS, V. J. R. M.; SILVA, F. B.; ACIOLI, M. F. Produção de Histórias em Quadrinhos na abordagem interdisciplinar de Biologia e Química. RENOTE, v. 10, n. 3, p. 18, 2012.

SILVA, C. R. L.; FALKEMBACH, G. A história em quadrinhos como recurso didático. Manancial Repositório digital da UFSM, Rio Grande do Sul, 2010.

SOUZA, S.S. O uso de história em quadrinhos no ensino de Biologia: uma alternativa para o estudo do conteúdo de respiração celular aeróbia. SEPT/UFPR, Curitiba, 2015.

ZURAWSKI, R.L; BOER, N; SCHEID, N.M.J. O professor e os novos contextos de ensino: uma abordagem teórico-metodológica em tempos de pandemia. DisciplinarumScientia| Ciências Humanas, v. 21, n. 2, p. 81-93, 2020. 